\title{
Environmental Issues Related to the Elderly and Physically Disabled People in Different Life Situations
}

\author{
Dušan Katunský ${ }^{\mathrm{a}}$, Carsten Brausch ${ }^{\mathrm{b},}$ \\ ${ }^{a}$ Department of Architecture and Building Structures, Institute of Architectural Engineering, \\ Faculty of Civil Engineering, Technical University of Kosice, Slovak Republic \\ ${ }^{\mathrm{b}}$ LVR - Integrationsamt Landschaftsverband Rheinland, Köln, Germany

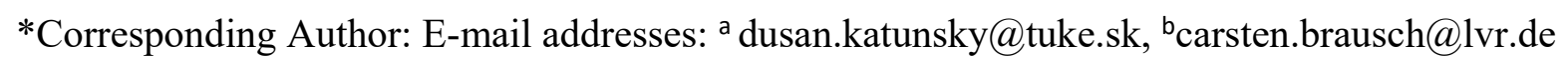

\section{ABSTRACT}

In Europe we can see a change in the social structure in the last period. Average life expectancy has increased dramatically over the last 50 years. Because of the improved life situation and advanced level of health care, older people are slower. With advancing age, the likelihood of experiencing a variety of constraints such as visual impairment, reduced hearing or physical ability increases. In such a life stage tenants are often forced to leave their long-term living space because these homes can not serve "new" individual needs and the resulting personal protection goal. This transition from the privacy of their home to the new environment often appears to be a painful change. They will take their familiar and well-known surroundings, because their homes can not be adapted to serve new needs. It must be the policy's role to create a new inclusive social space and the requirement for architects and designers to create new goals for the design of an adaptable environment. This is a comprehensive approach to the design of the outer and inner space that could serve people even if there is an unexpected situation and changes in movement and physiological limitations of older people. The contribution shows the results of the survey conducted in Germany and Slovakia. In the survey respondents expressed their opinion on what they considered important in creating an adaptive environment. Results are processed graphically with explanation. The results were mainly for designers and developers of the indoor environment. Based on the results of the questionnaire survey, studies of possible modifications in the interior of the flats were then prepared. The contribution yielded these results in three age groups of respondents; i. people aged 35, 50 and over 50.

Keywords: Demographic change; Barrier-free Design; Living Space; Quality of Life; Specific Needs; Modular Home Design 


\section{Introduction}

The EU is experiencing demographic change, resulting in a change in the social structure. People live longer and fertility decreases. This changing structure in Europe poses special problems for designers and apartment builders. A new approach to real estate design must be designed and implemented to suit the future needs of the people at all stages and to enable residents to remain self-sufficient in the "house" for as long as possible. At the earliest stages of the proposal, the typical requirements for each phase of the future citizens' future life must be considered. This is especially true for people with special protection needs, such as those with visual or hearing disorders. Spaces for different phases of life were dealt with by Brausch [1]. It was based on its considerations under various regulations [2], [3] and also the Stockholm Declaration of EIDD [4]. He also conducted a survey of how people can cope with different life situations and how it affects their environment.

It is important that the survey highlights the importance of housing in European society. It is clear that the house is more than protection against climatic conditions and individual retreats for people and families. The way of living has changed in Europe. In most EU countries, it is necessary to anticipate barrier-free when designing the home or working environment. [5]

Moving home is a crucial step in gaining personal independence. People tend to get involved in designing their first home many times before it finally becomes reality. We anticipate the different needs and desires that we then have to adapt, given the hard constraints of space and money. We have to get rid of our "personal style".

The demographic trend changes the social structure in Europe, changing the medium and long-term requirements for the development of residential users. For designers and homeowners, it would be good to consult with these needs to avoid vacancies and to create customized living spaces that will allow residents to stay independent as long as possible in their own home [6]. Therefore, it is necessary to use the rules for a barrier-free living environment [7], [8] already in the proposal.

Demographic change is a primary issue in the EU, because it is becoming increasingly clear that this change will create a diverse society. Those who take decisions in national parliaments are called upon to take action. Changing the average age of a company, which has an increasingly long life expectancy on the one hand, is on the other hand a lower birth rate. Statistically, the average life expectancy of newborns in Europe increases each year by two to three months. People live not only longer, but they also have increasing demands.

What is important for a survey is the definition of "barrier-free living space" [9], [10]. A survey of contemporary literature and related media quickly shows that the concept of availability is not clearly defined and is very versatile. Some differences in interpretation are due to translation from English. The very concept of availability is not well defined; therefore, several terms are used in the literature to represent it. Some terms are used for specific groups of customers, such as elderly people or people with disabilities. All of these concepts are a concept of availability and require a barrier-free design that is based on people's needs. (See Figure 1) 


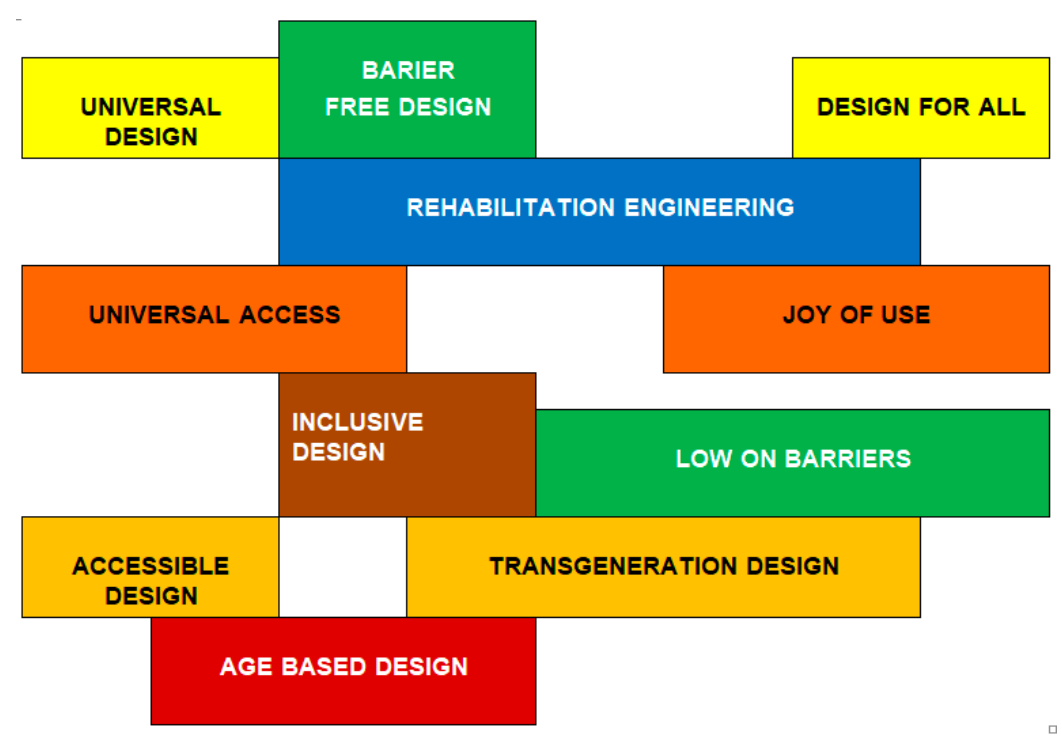

Figure 1 Tree of definition used

The following terms "barrier design" and "design for all" are considered to be the same. For consistency, the authors will use the term "barrier-free design" throughout the text. As a basis for the design and construction of seamless housing, designers must take into account the specific and individual needs of different user groups. Besides the basic requirements, it is necessary to take into account the needs of persons with specific protection objectives. The behavior of a person during life is characterized by different life stages and life requirements. Even a temporary change in health, for example due to a sporting accident, may reduce the availability of existing property that is not barrier-free. The fact that the limit of survival of the older age is displaced is shown in Figure 2, which shows the demographic forecast of the population in Germany in 2050. [11]

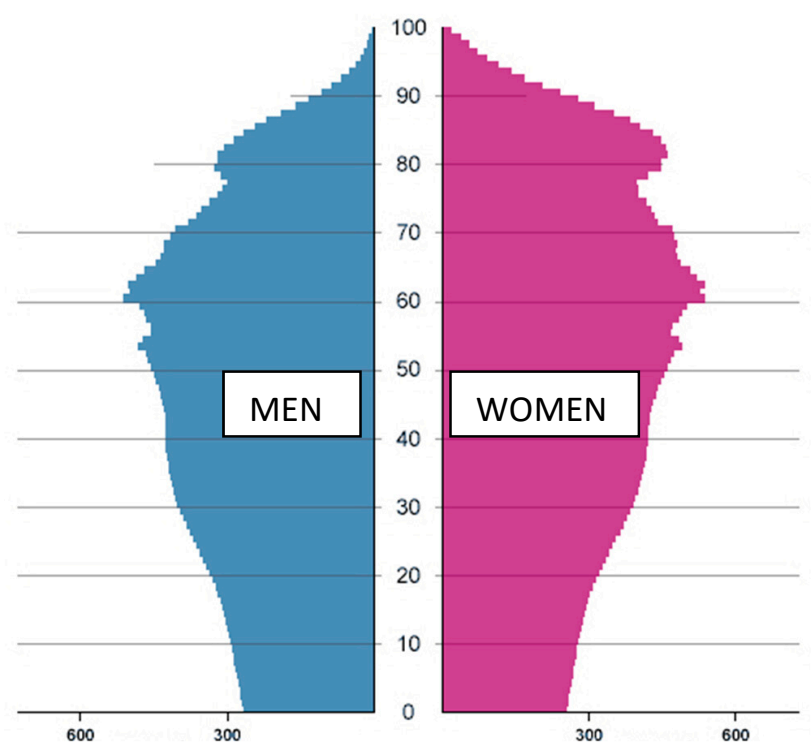

Figure 2 Population in Germany in 2050, X axis - thousands of inhabitants, Y axes - age [11] 
Architecture technology, including barrier-free, is often conducted with the concepts of green, sustainable, and so on design. [12].

The World Health Organization (WHO) has developed a classification to describe the functional health status, type and degree of disability, social disadvantage and relevant environmental factors under the heading "International Classification of Functioning, Disability and Health (ICF)".

A disability in the context of the ICF is the result of negative interaction between a person with a health problem and contextual factors on that person's ability to function. The ICF term disability is thus the generic term to cover any form of impairment.

The needs of people with disabilities are dealt with in various literatures. The area of the kitchen with special requirements is in [13], [14], [15]. The special problems of electronics with e - services and the use of computers are devoted to the [16], [17]. The general principles of designing barrier - free spaces are at [18], [19], [20], [21], [22], [23]. The design of the inner space for people with disabilities for different phases of life is dedicated to the source [24]. Social and multidimensional flats for the elderly are dedicated to authors in [25], [26], [27].

The most up-to-date information on this area of living space design for the remainder of 2018 is addressed in articles [28], [29] and [30].

In addition to living space suggestions for people with impaired movement, suggestions for people with sensory abnormalities should also be considered. In the future, it will be possible to activate the building, which means that buildings will be able to communicate with people using digital information to understand existing barriers. This latest trend in this area is devoted to the authors of the lectures [31], [32], [33], [34].

\section{Materials and methods}

As a method of research in this area, a questionnaire survey was conducted in two European countries in Germany and Slovakia.

Within field research, questionnaires were distributed to people of different ages; both in Germany and Slovakia.

The survey provides an overview of awareness regarding housing and living space. Based on the replies to 13 questions, statements on opinion, needs, and manner of dwelling can be made. The analysis of the results provides an interpretation of the needs and commercial viability of a modular and flexible living space design for all phases of life.

The response to the questions by the subjects took place without a special introduction on the topic of demographic change and its consequences on the design of living space. The questionnaire is shown in Figure 3. 


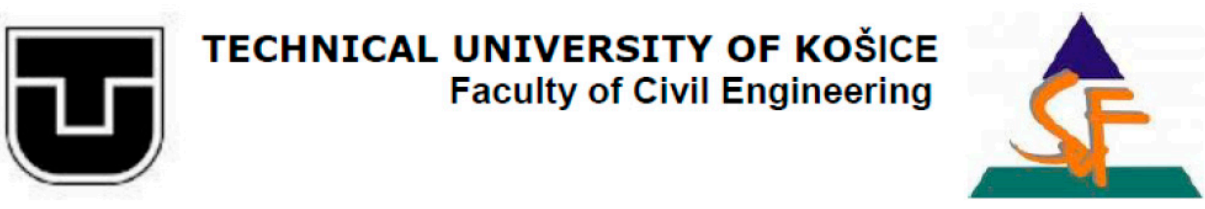

Questionnaire regarding the design of living space

If possible, please answer the questions in English.

1. Which age group do you belong to?

Up to 35 years 35 to 50 years more than 50 years

Г

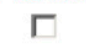

Г

2. From your current perspective, would the possibility of a modifiable floor plan represent an added value?
ГYes
$\Gamma_{\text {No }}$

3. How important is it for you to be able to stay in your current living quarters in spite of changing living situations?
Very important Important
Less important
Not important
Г
Г
$\Gamma$
Г

4. Which changing living circumstances can you think of that require an adaptation of your individual living space?

\begin{tabular}{|l|}
\hline 1. \\
\hline 2. \\
\hline 3. \\
\hline 4. \\
\hline 5. \\
\hline 6. \\
\hline
\end{tabular}

5. Which changing living circumstances could you foresee in the future requiring an adaptation of your living quartes? 
6. Do your current living quarters allow a variable reconfiguration of the rooms?

$$
\Gamma_{\text {Yes }} \quad \Gamma_{\text {No }}
$$

7. In how far are you willing to pay a higher rent for an adaptable/barrier free living space? How many percentage points can the costs be above the current market value of a not adaptable/barrier free living space?
$0 \%$
Up to $10 \%$
$10 \%-20 \%$
More than $20 \%$
$\Gamma$
Г
Г
Г

8. Which criteria are important for you in a good living area?
ГDoctors
$\Gamma$ Shops for daily needs
$\Gamma$ Sport facilities
$\Gamma$ Green areas, forests
$\Gamma$ Cultural offers
$\Gamma$ Public transport

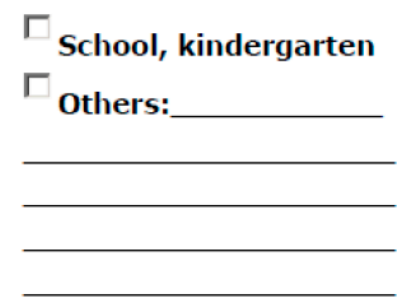

9. Which importance do you attach to which furnishings when choosing your individual living quarters?

\begin{tabular}{|c|c|c|c|c|}
\hline & $\begin{array}{l}\text { Very } \\
\text { important }\end{array}$ & Important & $\begin{array}{l}\text { Less } \\
\text { important }\end{array}$ & $\begin{array}{l}\text { Not } \\
\text { important }\end{array}$ \\
\hline No thresholds & $\Gamma$ & $\Gamma$ & $\Gamma$ & $\Gamma$ \\
\hline Balcony/ Terrace & $\Gamma$ & $\Gamma$ & $\Gamma$ & $\Gamma$ \\
\hline $\begin{array}{l}\text { Bathroom with plane } \\
\text { shower tub }\end{array}$ & $\Gamma$ & $\Gamma$ & $\Gamma$ & \ulcorner \\
\hline Elevator in building & $\Gamma$ & $\Gamma$ & $\Gamma$ & $\Gamma$ \\
\hline $\begin{array}{l}\text { Sufficient movement } \\
\text { possibilities }\end{array}$ & $\Gamma$ & $\Gamma$ & $\Gamma$ & $\Gamma$ \\
\hline $\begin{array}{l}\text { Emergency call } \\
\text { system }\end{array}$ & $\Gamma$ & $\Gamma$ & $\Gamma$ & $\Gamma$ \\
\hline $\begin{array}{l}\text { Parking space for } \\
\text { perambulator, bike } \\
\text { or walking frames }\end{array}$ & $\Gamma$ & $\Gamma$ & $\Gamma$ & $\Gamma$ \\
\hline
\end{tabular}


10. How important are potential service offers to you?

\begin{tabular}{|c|c|c|c|}
\hline Food/ Catering & y important & $\begin{array}{l}\text { Important } \\
\Gamma\end{array}$ & Less important \\
\hline $\begin{array}{l}\text { Transportation } \\
\text { services }\end{array}$ & $\Gamma$ & Г & $\Gamma$ \\
\hline Care services & $\Gamma$ & $\Gamma$ & $\Gamma$ \\
\hline Shopping assistance & $\Gamma$ & $\Gamma$ & $\Gamma$ \\
\hline Others: & г & $\Gamma$ & $\Gamma$ \\
\hline
\end{tabular}

11. Which technical supports are of special importance to you?

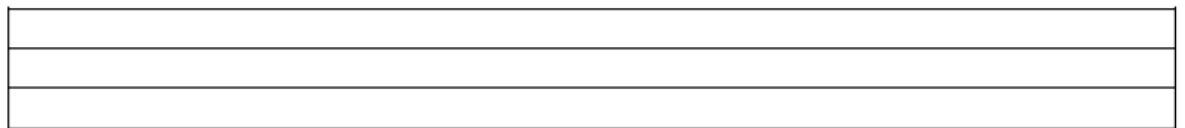

12a. Which of the below mentioned points are of special importance for you?

\begin{tabular}{ll}
$\ulcorner$ Step-free entrance & $\Gamma$ Clear door width \\
$\ulcorner$ Sufficient movement possibilities & $\Gamma$ Broad parking slots \\
$\ulcorner$ Covered entrance & $\Gamma$ Emergency call system \\
$\ulcorner$ Others & \\
\hline
\end{tabular}

12b. Which prioritization would you give to these points?

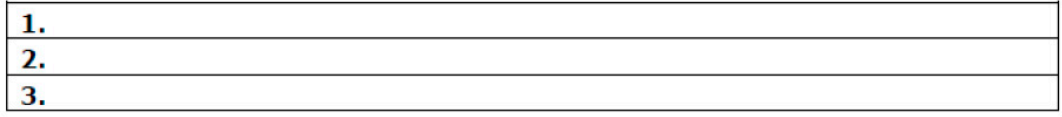

13. Is there anything else you would like to mention as important for the longest possible stay in your own living quarters?

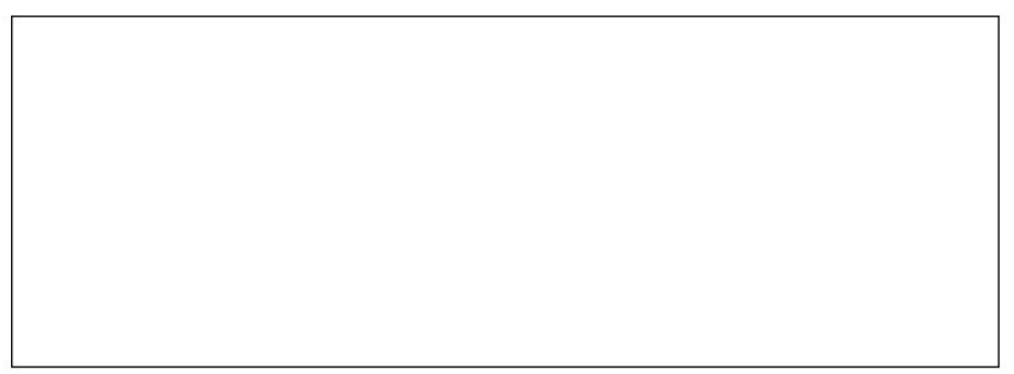

Figure 3 Questionare

\section{Discussion and results}

Specialist specialists have been avoided because they are not representative of ordinary users due to their high professional association.

Experts in the area were not addressed because they are not representative of ordinary users due to their highly professional knowledge of real estate.The purpose of these questions is to 
confirm the arguments provided on the basis of the data reviewed, pointing to the need for a modular and flexible design of living space for all phases of life. The three-page questionnaire can be seen in Figure 3. The following statements can be taken on individual questions and the results can be evaluated as follows.

\section{Question 1: Which age group do you belong to?}

The answers to the first question allow group members to be grouped into one of three age groups. This differentiation is important for analyzing some issues, as it is to be expected that different age groups will expect different life situations in the future and will have priorities for other requirements. In particular, it is expected that there will be differences between the age groups in response to the question of the expected technical aids.

Three age groups were provided:

- Up to 35 years

- 35 to 50 years

- More than 50 years

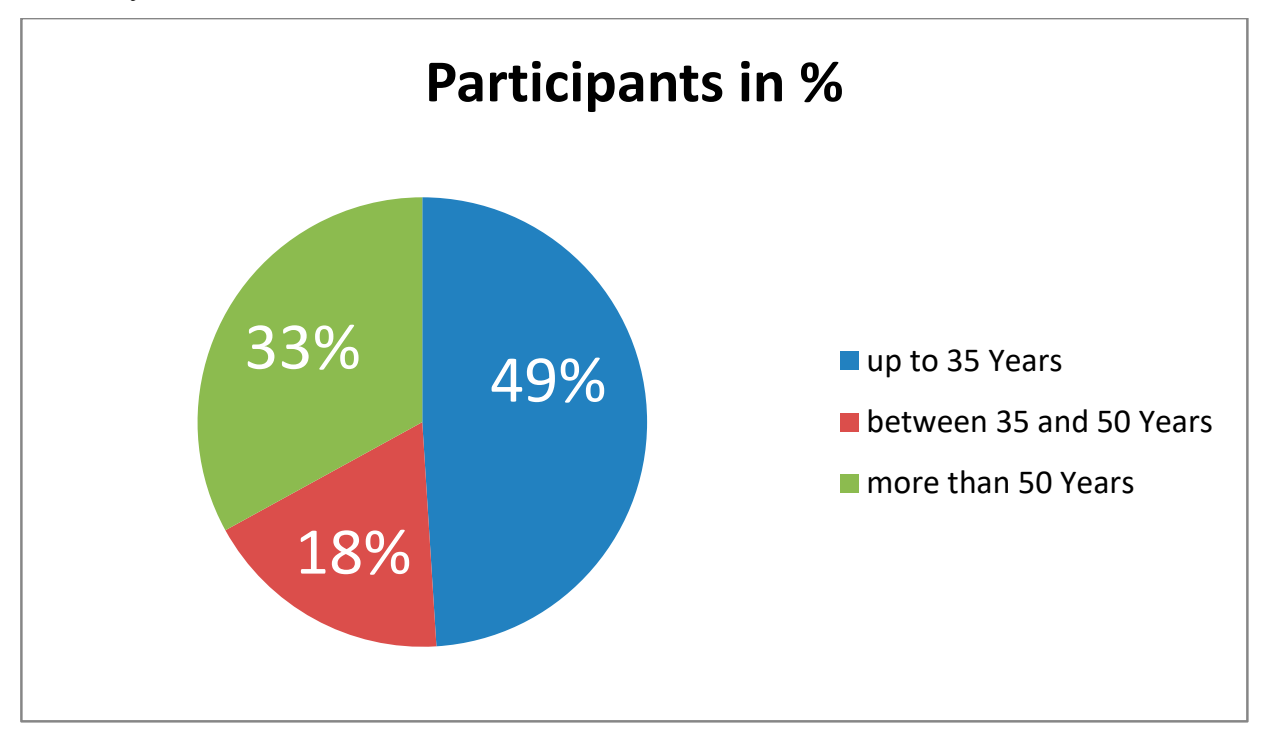

Figure 4 Classifications in age groups, participants of questionare in percent

\section{Question 2: From your current perspective, would the possibility of a modifiable floor plan represent added value?}

In the second question, the participants were asked if the possibility of a modifiable floor plan would represent additional value from their current perspective.

$95 \%$ of the participants responded yes; only $5 \%$ no. This result shows the awareness within society and the expressive desire for a flexible, adaptable living space and the resulting demand for such. 
It can be assumed that the participants will choose in a future change of living space a flexible floor plan over a fixed one, at least as long as the other prerequisites are similar.

Question 3: How important is it for you to be able to stay in your current living quarters in spite of changing living situations?

The responses to this question clearly show (as they do in question 2) the wish of the participants to remain in their living space as long as possible. For the real estate agent, this means that if he or she offers a flexible, adaptable building suitable at all phases of life, sustainable marketing and long-term stay of the user is likely.

If one combines the results for the replies very important and important, $91 \%$ of participants wish to remain in the own four walls. Analysis of the responses shows that the replies less important and unimportant are rarely used. Only 7\% consider the possibility to remain in their own living space to be less important and $2 \%$ unimportant.

These results are schematically illustrated in the following Figure 5.

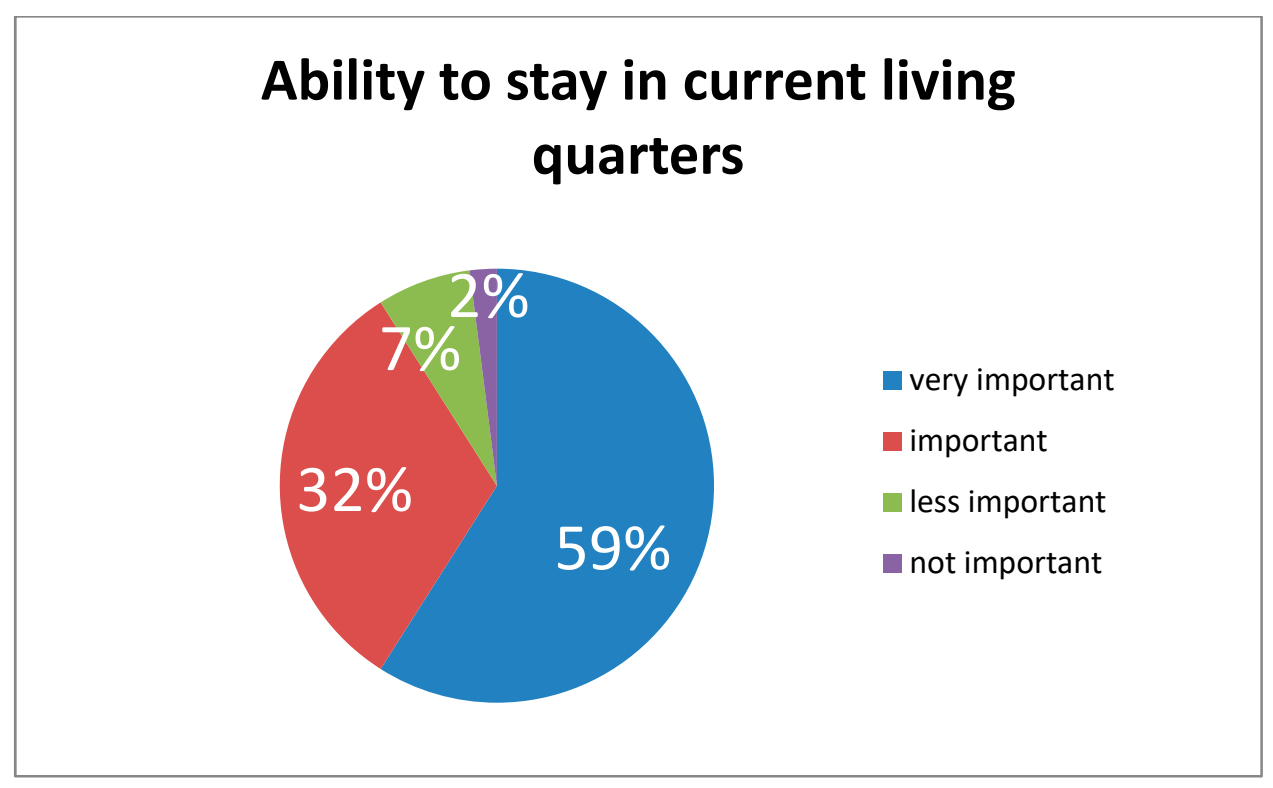

Figure 5 Ability to stay in the current living quarters

\section{Question 4: Which changing living circumstances can you think of that require an adaptation of your individual living space?}

In the responses to this question, several circumstances are mentioned by the various age groups depending on the phase of life. Those below 35 years of age often mention planning for a family or changes in the employment situation. Those between 35 and 50 consider that children will leave home soon. Those above 50 no longer require office rooms and consider the upcoming need to take care of sick or disabled relatives. All these criteria have a direct effect on the space requirements. 
Table1. Informative to separate the responses by age group

\begin{tabular}{lll}
\hline Age up to 35 & Age 35 to 50 & Age more than 50 \\
\hline Marriage & Becoming elderly & Visually impaired \\
Child & Increase of disability & Hearing impaired \\
Economic improvement & Sudden illness & Walking difficulties \\
Illness & Recording a need relatives & Physical disable \\
Accident & Accident & Loss of partner \\
Job change & Issue of childs & Dementia \\
& & Nursing personal \\
& & Room of no longer needed \\
& & Accident \\
\hline
\end{tabular}

Question 5: Which changes living circumstances could you foresee in the future requiring an adaptation of your living quarters?

The responses to questions 4 and 5 were analyzed together. Here it is informative to separate the responses by age group. This is illustrated in Table 1 .

\section{Question 6: Do your current living quarters allow a variable reconfiguration of the rooms?}

Of the all participants $32 \%$ answer yes and 54\% no if consider their current living space to be flexible. However, one needs to be aware that the interpretation of flexible can vary significantly.

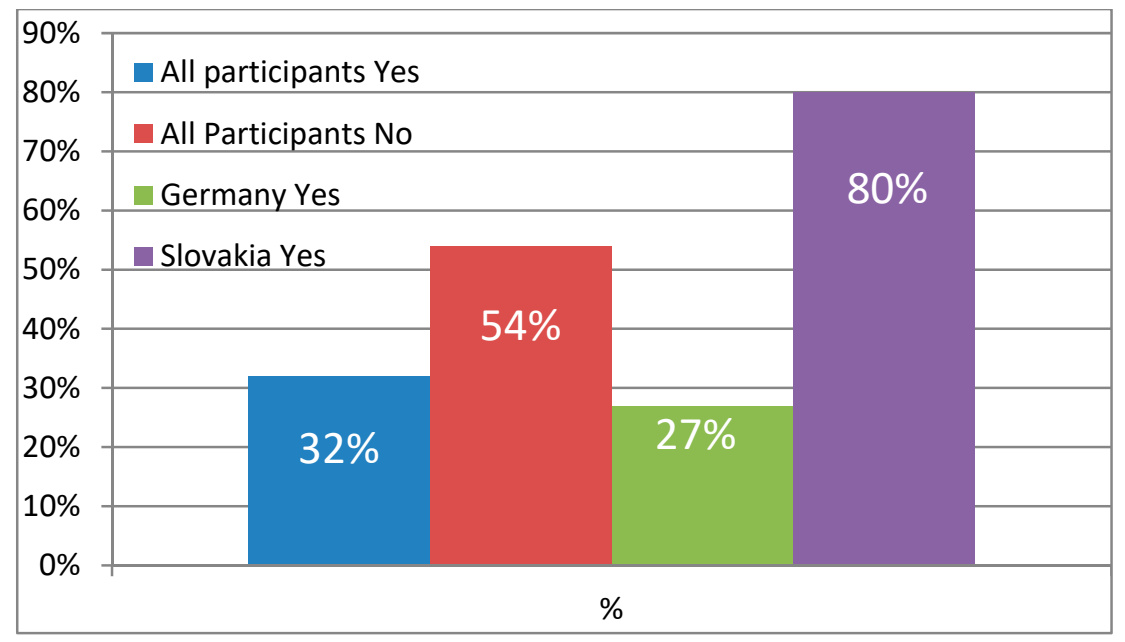

Figure 6 Is your apartment flexible, adaptable?

Noticeable when analyzing the data for this question were the different responses between Slovakian and German participants. It was seen that $80 \%$ of the participants from Slovakia consider their current living space changeable, but only $27 \%$ of the German participants. It can only be speculated whether Slovakian participants have a higher willingness to rebuild. Another potential explanation could be the skeleton construction type buildings that have been erected in 
Slovakia in the last few decades, which have already formed the basis for flexible building. These buildings enable an increased flexibility compared to other construction types. With this construction style, the structural weight of the buildings is carried mostly by columns and dropstructures. Load-bearing walls, which are not changeable or only changeable with major effort, are rarely present in this building style.

Question 7: In how far are you willing to pay a higher rent for an adaptable/barrier free living space? How many percentage points can the costs be above the current market value of a not adaptable/barrier free living space?

How important the participants consider a flexible and barrier-free living space can be seen by their willingness to pay a higher rent.

Only approximately $12 \%$ of the participants are unwilling to pay a higher rent or costs for a variable and barrier-free living space compared to an inflexible one. About $40 \%$ of the participants would be willing to pay up to 10 percentage points more and another $40 \%$ up to 20 percentage points more. Approximately $9 \%$ were even willing to pay more than 20 percentage points more than the standard price. With this willingness to pay more for a barrier-free and variable living space, the users declare the value of these advantages. Surely this outcome also mirrors the knowledge that the increased construction efforts come with increased costs.

Calculated for the length of stay in a building, the initially higher costs are certainly less than the sum of the necessary rebuilding (if possible at all).

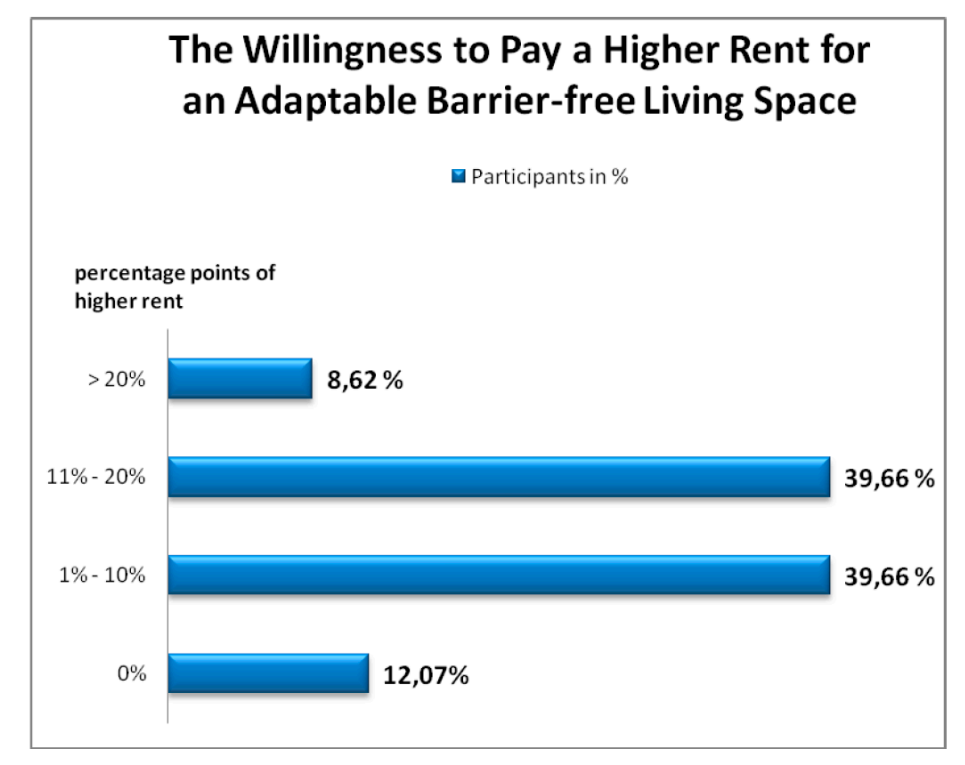

Figure 7 The willingness to pay a higher rent for an adaptable

\section{Question 8: Which criteria are important for you in a good living area?}

In this question seven parameters defining the location of the living space were provided, multiple answers were possible. In addition a free text answer was possible under "other". 


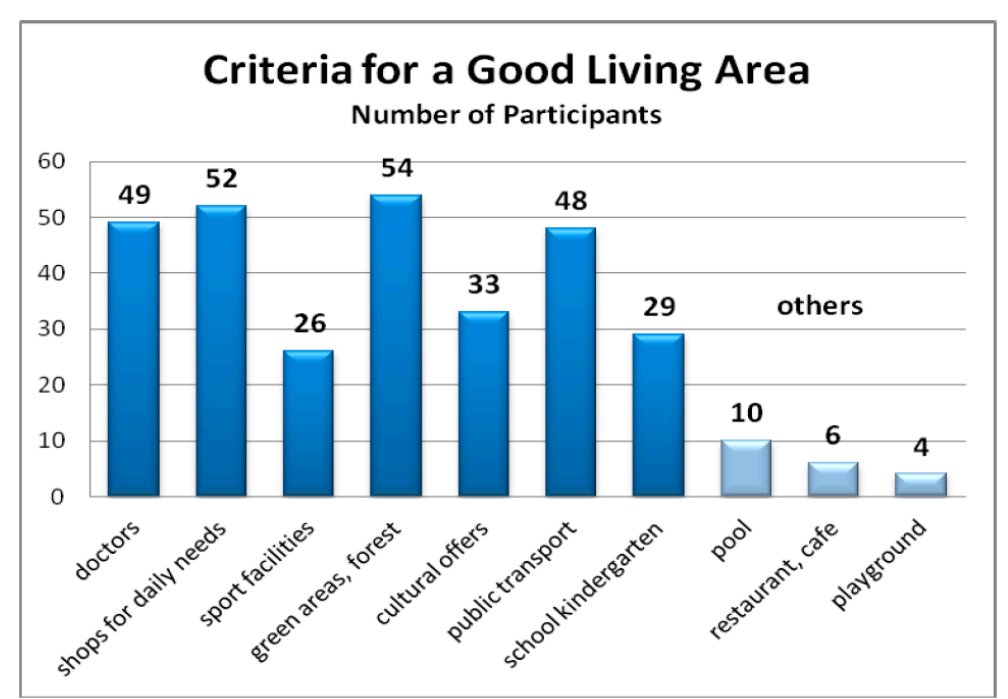

Figure 8 Criteria for a good living area

The results show clearly how important outside areas such as gardens and forests are for the users. The need to move in nature is major. This is also confirmed in the other questions where many participants wish for a garden, balcony, or terrace. At the same time, a central location is also of importance. The presence of medical doctors, shops for daily needs, and an efficient connection to public transport are considered part of a good living location. The availability of a school and kindergarten is considered necessary by the younger participants. In the following questions the participants from the higher age group also request a cross-generational living space and a mixture of inhabitants of all age groups. As additional parameters a pool, cafe/restaurant, and playground were mentioned.

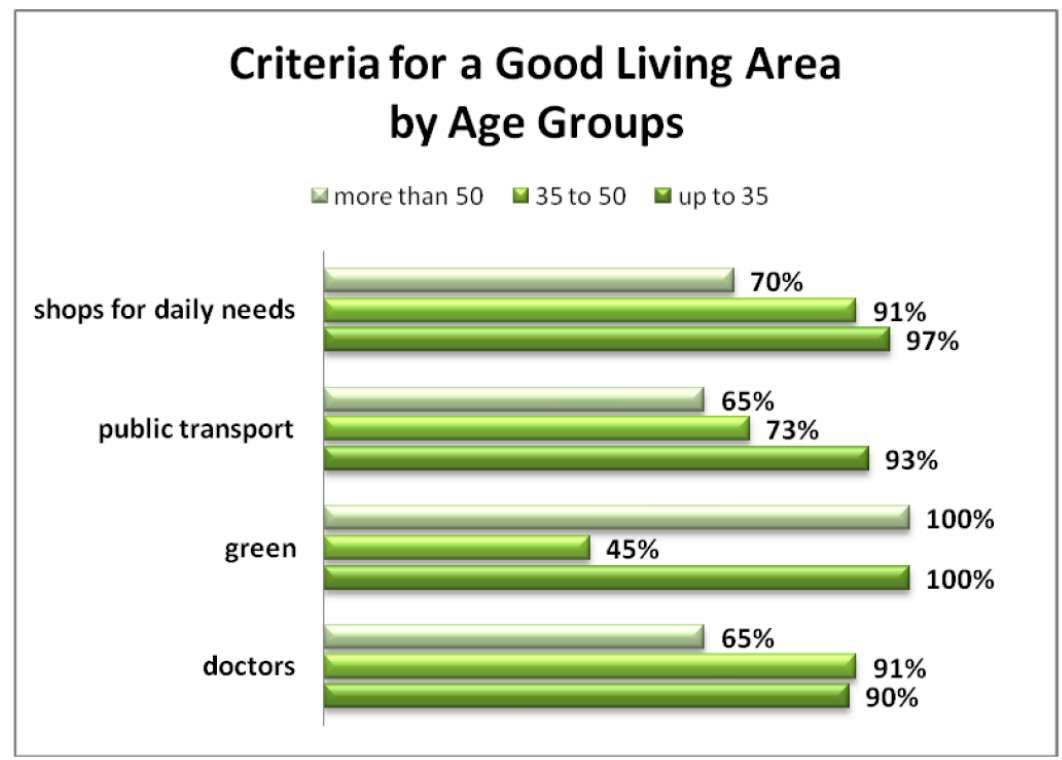

Figure 9 Criteria for a good living area by age groups 
A detailed analysis according to age groups confirms the results obtained so far. All responders below 35 and above 50 consider green areas-gardens, parks, forests-very important for the choice of the location of their homes. All four criteria shown are considered to be very important.

This clearly shows the desire to live in a functioning infrastructure with an efficient public transport system, and this across all age and life phases. The house builder is well advised to consider all these criteria during the planning and building of living space.

\section{Question 9: Which importance do you attach to which furnishings when choosing your individual living quarters?}

This was a multiple choice question. The responses show which fittings are of special value to the participants. Seen to be of high value is the presence of a bathroom with a ground level shower stall, which is an excellent example of a demand that is independent of the age range and provides an advantage for all. Likewise, the availability of a balcony or an outdoor sitting area is in high demand. If necessary, it is of importance for the users to have an alarm system at their disposal, which shows the demand for a secure living space.

The level constructions of the rooms with a sufficiently large area for keeping strollers, bicycles, walking frames, wheel chairs, etc. are considered important as well, which should be considered in the planning and construction of barrier-free living space. The presence of an elevator is another major item. If not available from the start of building, the construction should take into account the potential to retrofit an elevator. Remarkably, these features are in demand independent of age, which shows that barrier-free equipment has advantages for all.

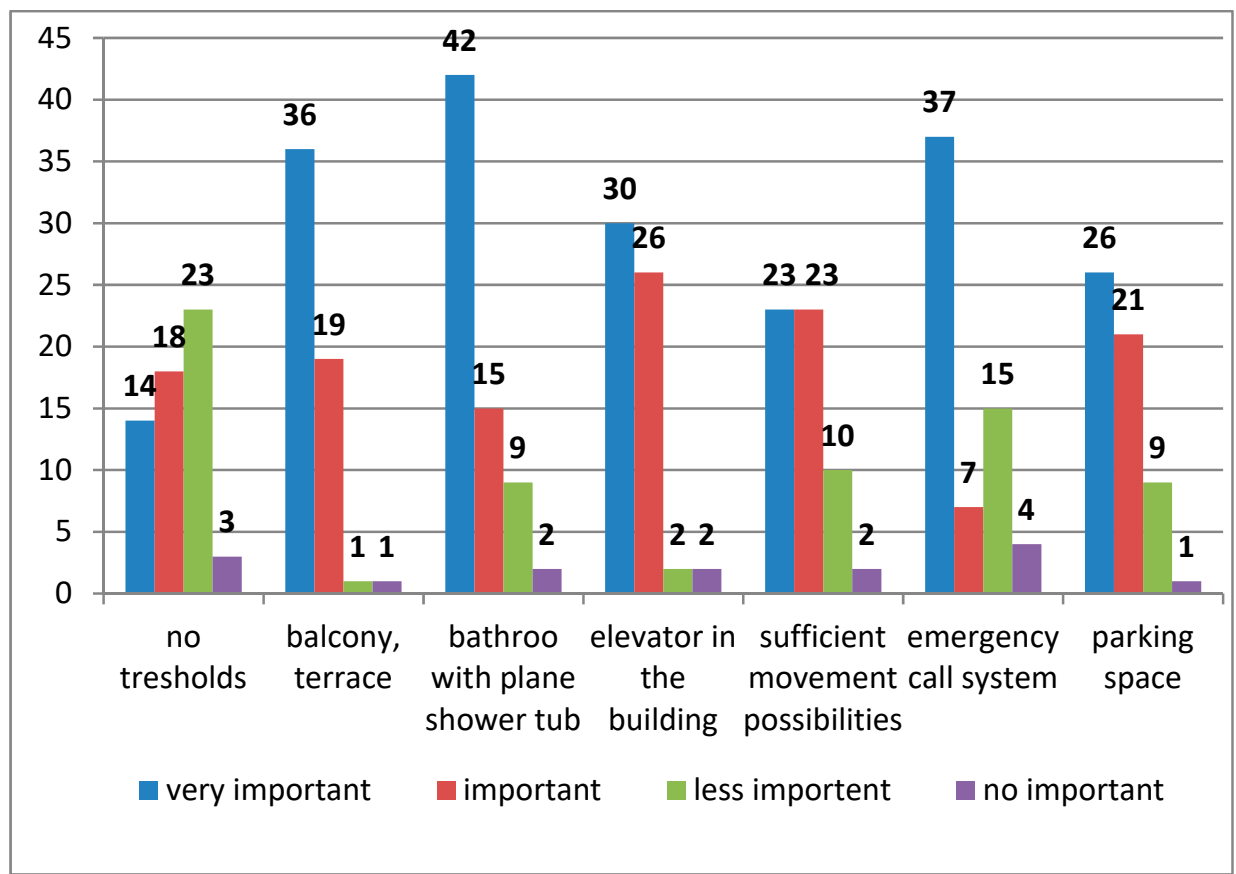

Figure 10 Importances for choosing the individual living quarters 


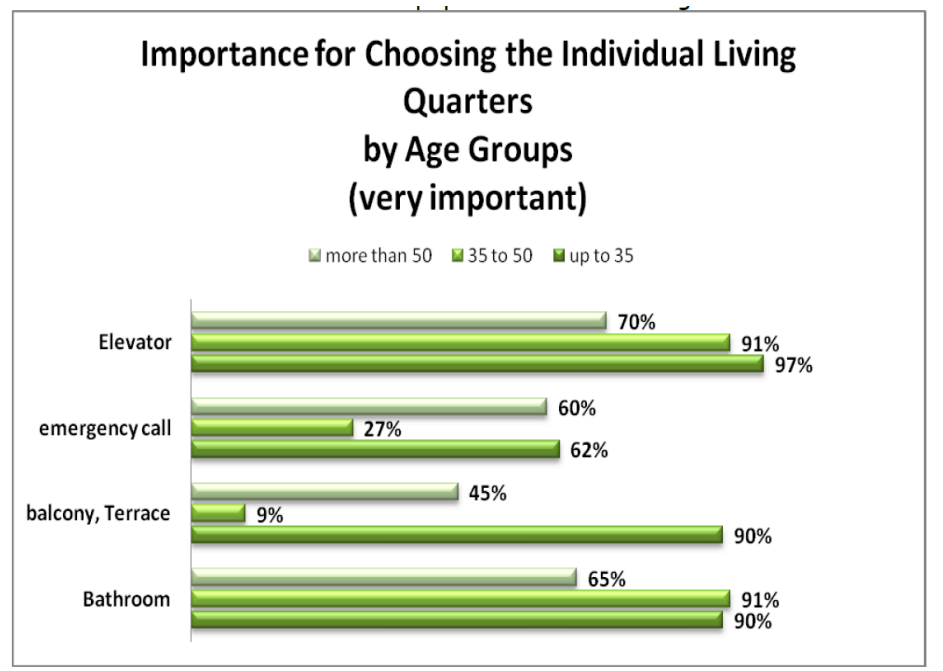

Figure 11 Importances for choosing the individual living quarters by age Groups

Elevators and a barrier-free bathroom appeared to be very important for all age groups. The groups below 35 and above 50 considered the availability of a balcony or terrace to be very important. Also, in the prioritization of an emergency call system both age groups responded similarly.

\section{Question 10: How important are potential service offers to you?}

The question regarding the importance of potential service offers was answered as follows:

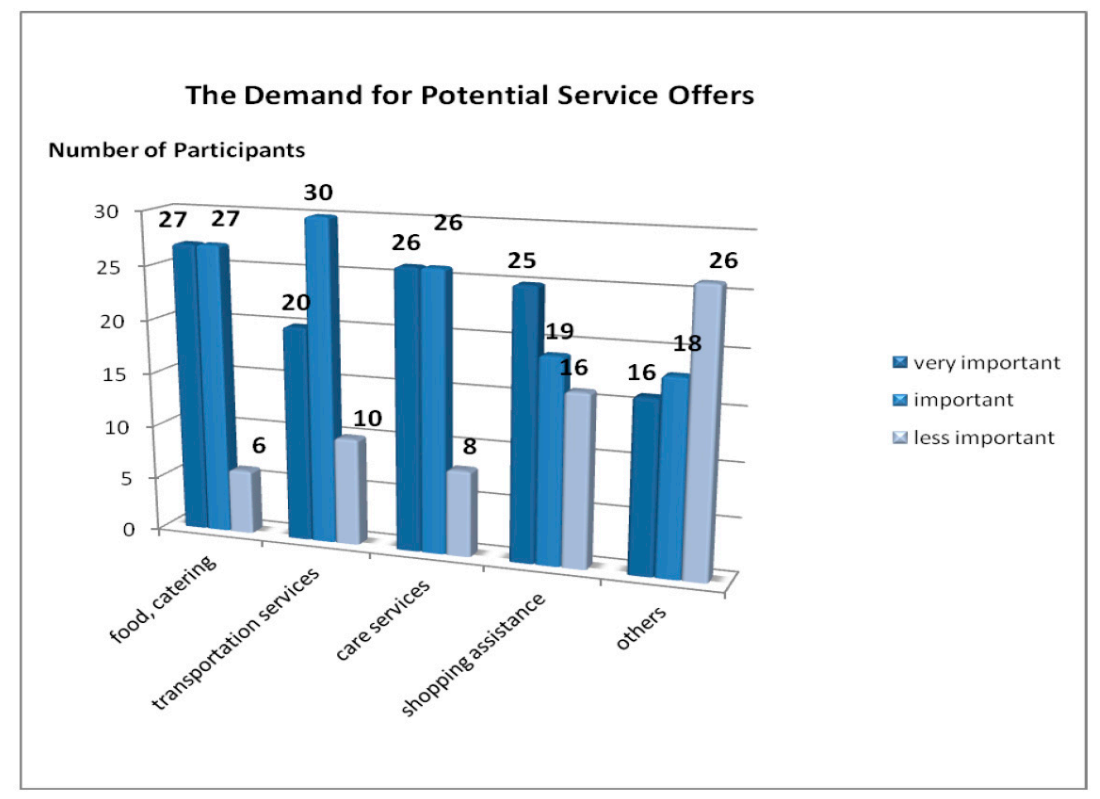

Figure 12 The demand for potential service offers 
The availability of transportation services was the most demanded service, with 30 participants considering this very important. Nearly as many, 27 participants, see the offer of food and catering as very important.

When assigning the relative importance of the questions, multiple answers were possible. Assessment of the different age groups shows the specific priorities. Those below 35 consider the services food, catering, and transport as very important. Obviously, what they currently consider a luxury is often later on considered a defined need. However, this age group is also sufficiently forward-looking to consider care services as very important. The group between 35 and 50 is less clear in considering something as very important. Relative importance is given to catering, care, and shopping services. The group above 50 considers the care services as most important. The other services are not seen as very important. Participants also mentioned cleaning and laundry services as well as support for garden/outdoor area work.

Planners and designers should, early on, make potential tenants aware of the service offers available. Finally, it has to be mentioned that these services are not provided by the landlord, but can be a significant criteria in the choice of the location for a dwelling and can be a competitive advantage.

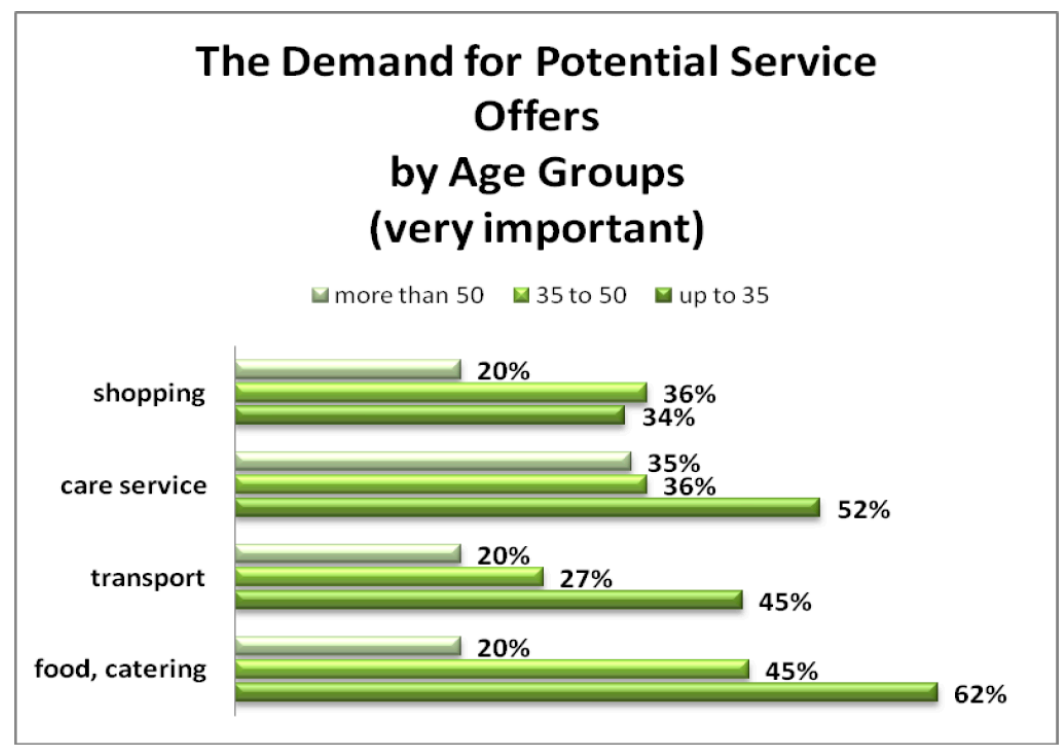

Figure 13 The demand for potential service offers by age groups, Carsten Brausch

\section{Question 11: Which technical supports are of special importance to you?}

This question did not provide answers to choose from, but provided an opportunity to voice the personal needs of the participants, who named the technical aids to be of special importance to them. The following technical aids were mentioned:

- High speed Internet access

- Television access in several rooms

- Environmental control 
- $\mathrm{AAL}$

- Ground level shower stall

- Raised lavatory seat

- Elevator

- Emergency call

- Bath tub lift

- Stair lift

- Electronic window shutters

- Height adjustable bed

The responses show a degree of basic knowledge about the potential technical aids available. Some technical aids for the realization of barrier-free living space, like the stair lift, are mentioned several times. Other demands are described by the desired function, like the environmental controls. Separated by age groups, it can be seen that those below 35 mostly name the Internet, TV, and emergency call systems. Those between 35 and 50 as well as those above 50 mostly select elevator, stair lift, bath tub lift, and AAL. Those above 50 also chose handles in the bathroom and height-adjustable beds. Throughout the whole questionnaire, well-known technical aids like stair lifts or bath tub lifts are named.

It can be seen that there are demands which can be added with relatively little effort, but also some which have to be considered early on in the planning and construction phase. In the meantime, many more innovations are available on the market.

\section{Question 12a: Which of the below-mentioned points are of special importance for you?}

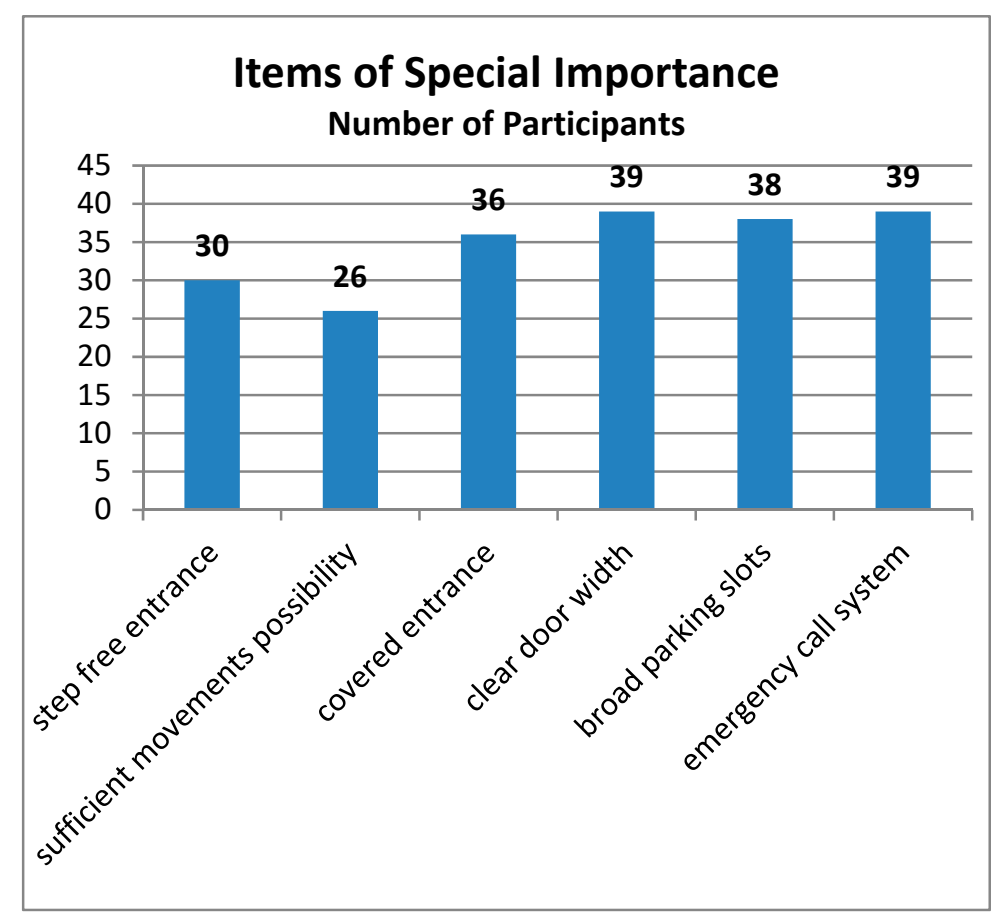

Figure 14 Items of special importance 
It can be seen that all suggested items are considered important by the participants. The most frequently mentioned items are clear door width and emergency call systems. A well-illuminated entrance area was also mentioned, which is an important note that should not be forgotten.

By the high value placed on the above answers, the participants display a comprehensive awareness of barrier-free living space.

\section{Question 12 a+b: Which prioritization would you give to these points?}

The analysis of the prioritization shows that emergency call systems are considered to be the most importance. For the second most important item, the answers are country-specific, with the Slovakian participants mentioning broad parking slots and the German participants mentioning clear door width. This again shows that barrier-free design must be taken into account in the planning phase. In third place, a covered entrance and sufficient movement areas are mentioned. All responses range closely together, which shows that all of these points have to be considered in the realization of barrier-free design of living space.

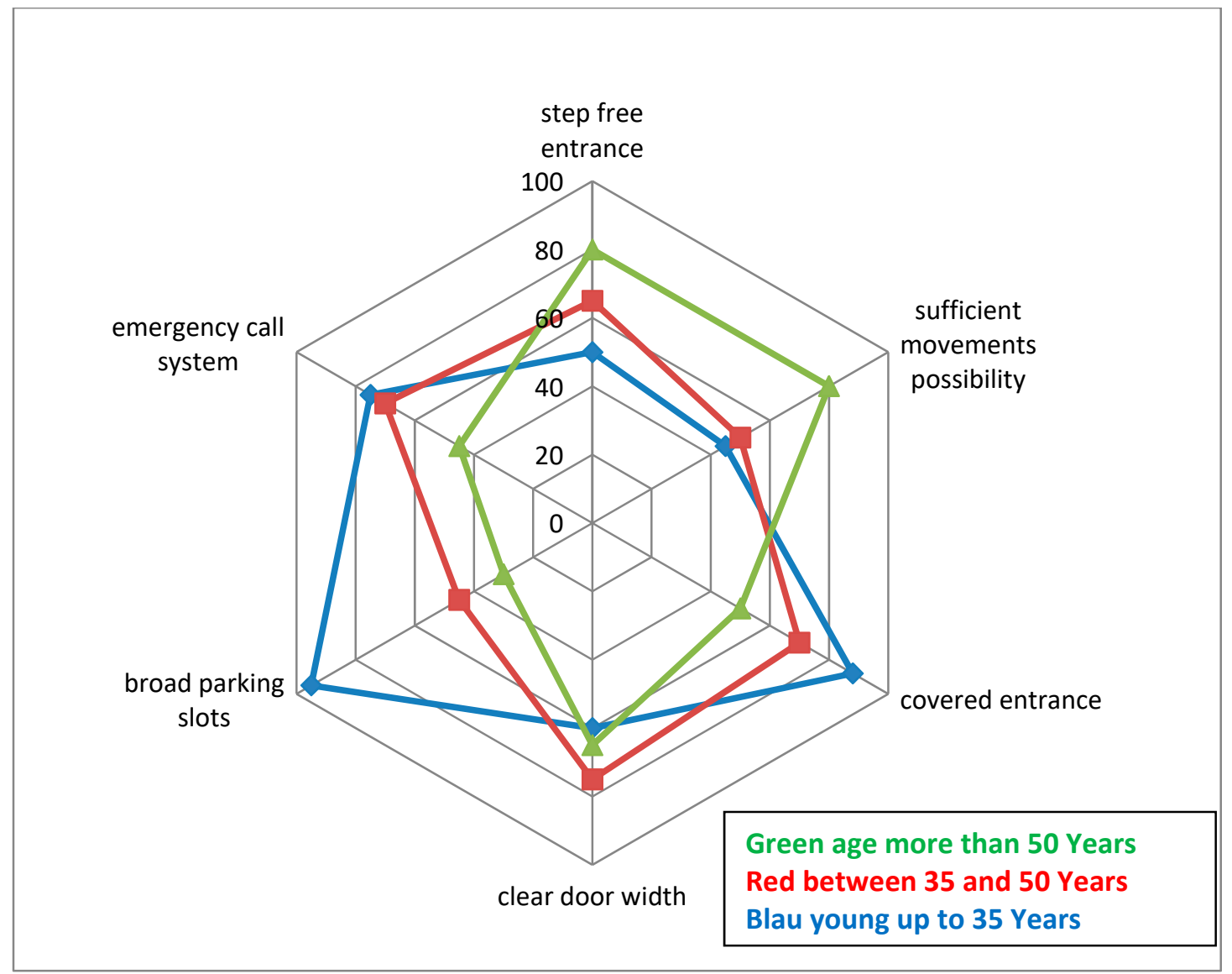

Figure 15 Special importance of the mentioned points: Prioritization by age groups [\%]

For this question, a more detailed analysis separated by the prioritizations according to age groups is helpful. In the radar diagram shown below, the various needs are clearly depicted. The age group below 35 clearly prioritizes broad parking slots, a covered entrance, and an emergency 
call system. The age group between 35 and 50 favors, clear door widths, and the emergency call system. The group above 50 emphasizes mostly sufficient movement's possibility and a step-free entrance; clear door widths. Emergency call systems, broad parking slots and a covered entrance are considered equally important but are mentioned as third in priority.

It is clear that for different age groups the importance of the various needs is different. Overall, the aim is barrier-free site development.

In the building of barrier-free living space, it is especially important to consider those requirements that later cannot be adapted or can only be adapted with major effort, e.g., step-free entrance, clear door width, and sufficient movement areas.

\section{Question 13: Is there anything else you would like to mention as important for the longest possible stay in your own living quarters?}

This free-text question provides an opportunity for the participants to name important points not specifically included. The following points were mentioned:

- Good neighborhood

- Clean, well-tended surroundings

- Good location

- Family contact

- Home care

- Cross-generational living

- Preservation of independent living

- Intercom with video screen

- Room for visitors

- Potential for private retreat

- Well-being

Here, the importance of the location and surroundings is stressed again. Besides the demand for a green environment and sufficient infrastructure, the participants place high value on welltended surroundings and a good neighborhood. One participant referred to this as well-being. High priority is also given to privacy and the preservation of independence.

\section{Conclusions}

Optimization results from the questionnaire evaluation and shows that participants have a high level of awareness of the different stages of life and resulting changes in the life situation. Different age groups expect specific changes in the life situation. Planning parenting is often a key aspect for people under 35 while people aged 35-50 often consider moving an adult child or relocating a relative in need of help more likely. Over 50 years of age are most concerned about possible health disorders and have knowledge of possible solutions. This group has changed in recent years - the number is rising and often in good financial condition, they are an important goal for the real estate market. No longer satisfied with a small one-room flat, more than 50 years prefer: 
- Flexibility

- Innovations

- Independency

Health is not taken for granted and is considered of high value. However, most people avoided linking the change in situation and resulting needs to age or disability. Everyone has a well-developed, individual sense for what is good for them and what is of personal benefit.

The responses in the questionnaires clearly show the age-specific needs and uncover a multitude of varying expectations. The number of potential occurrences increases the likelihood of changes in living situation. Only an adaptable and flexible changeability of living space can then assure the possibility to remain in one's own dwelling for a long time. If you consider this investigation as a basis for planning and the requirements mentioned, a good guideline for the design of barrier-free and flexible living space can be drawn up. The desk research has already shown the demand for variable, flexible living space. This field research confirms this and stresses the need for barrier-free, flexible living possibilities. The next chapter shows the feasibility and the possibility of a flexible floor plan design and explains this in examples.

Health is not considered to be obvious and is considered to be very valuable. Most people, however, have avoided interconnecting the changing situation and resulting needs with age or disability. Everyone has a well-developed, individual sense of what is good for them and what personal gain is.

The answers to the questionnaire clearly show the needs of age and reveal different expectations. The number of potential occurrences increases the likelihood of changes in the life situation. Only an adaptable and flexible change of living space can ensure your stay in the apartment for a long time. If you consider this investigation to be the basis for the planning and the stated requirements, good guidelines for barrier-free and flexible living space design can be developed. Table research has already shown the need for a flexible and flexible living space. This field research confirms this and emphasizes the need for barrier-free and flexible living opportunities.

Requirements for a barrier-free environment can easily be expressed through certain principles that need to be met:

- exterior, development of the building / free entrance area

- entry to the ground without obstacles

- larger entrance shelter

- sufficiently clear door width (minimum $1.00 \mathrm{~m}$ )

- automatic door opening

- the handle / control is $85 \mathrm{~cm}$ high

- ramp inclination at max $6 \%$, planing railings and pillars / curbs, height of view $150 \mathrm{x}$ $150 \mathrm{~cm}$ after $6 \mathrm{~m}$

- if board ramps are foreseen, plan a sufficient moving area in front of the door,

- design with high contrast, flat heads and perceived areas,

- areas with free movement $150 \times 150 \mathrm{~cm}$

- provided sufficient light intensity 
- if stairs are required for entry

The stairs can be designed to be easily visible by contrasting construction and should be suitably tangible by placing a well-placed railing and attention area before the first step.

- and others (according to the results of the questionnaire survey)

Similar principles apply to interior design. If possible, we will inform you in other articles about the possibility of realizing the flexibility of the ground plan, the design of the flats for the barrier-free apartment type and will be explained in the examples below. In addition to suggestions for people with impaired movement, consideration should be given to suggestions for individuals with sensory abnormalities. The approach described in the rules is the principle of two senses. In addition to visual cognition (tactile), tactile (touching) and auditory (hearing) knowledge is also used. The two-sided principle says that if two of the three senses are solved in the building, it is considered as barrier-free for $90 \%$ of all users.

In the future, it will be possible to activate the building, meaning that buildings will be able to communicate with people using digital information to understand the barriers present.

The aim is to enable all individuals to use their living space without difficulty and, most importantly, without external assistance, by incorporating a barrier-free design.

\section{Acknowledgement}

This contribution was developed in connection with the research project VEGA 1/0674/18 of the Scientific Grant Agency of the Ministry of Education, Science, Research and Sports of the Slovak Republic and Slovak Academy of Sciences.

\section{Author contributions:}

Dušan Katunský wrote the article, distributed a questionnaire in Slovakia and evaluated the results of some data, made conclusions. The author of the questionnaire is Carsten Brausch, who distributed the questionnaire in Germany and evaluated the results. Both authors communicated when evaluating the results and mutually endorsed the results and procedures. The authors have prepared another part to design flexible living space for old and disabled people.

\section{Conflicts of Interest:}

The authors declare no conflict of interest.

\section{References}

[1] Brausch, C. Advantages and Feasibility of a Modular Home, Design for All Phases of Life, thesis, Technical University of Kosice, 2015, Slovakia

[2] Bundesministerium für Wirtschaft und Technologie Strategiemappe "Zukunftsmarkt 50 plus", Münster, Faktenblatt 3, Page $3 ; 2010$

[3] Wohnen im Alter, Bundesministerium für Verkehr, Bau und Städteentwicklung, ISBN 3-87994479-8, Berlin 2011

[4] Stockholm Declaration EIDD. 2004, Sweden 
[5] Katunský, D.; Lopušniak,M. Interaction of selected parameters within design of suitable working environment, HB 2006 - Healthy Buildings: Creating a Healthy Indoor Environment for People, Proceedings 3, pp. 147-152 Lisboa Portugal 2006

[6] Gutjahr, U., Barrierefreie Bau- und Wohnkonzepte, ISBN 978-3-86586-299-7, Forum Verlag Herkert GmbH, 7. Aktualisierung 2012

[7] Loeschke, G. et al. Barrierefreies Bauen Band 1 Kommentar zu DIN 18040-1, ISBN 978-3-41020544-9, Beuth Verlag Berlin 2012

[8] DIN Seminar, Fachplaner Barrierfreies Bauen, Skript Monika Holfeld, Beuth Verlag Berlin 2013

[9] Kopf, K.; Kanzian,D. Die wahren Barrieren sind im Kopf, in: Konstruktiv No: 05, Verlag Berlin 2011, Germany

[10] Krajewski, C., Von Barrierefreiheit zum Design für Alle Erfahrung aus Forschung und Praxis, Arbeitsgemeinschaft Angewandte Geographie Münster e.V., 2. Auflage Münster, 2009; ISBN 9783-9810969-4-1, Page 12

[11] Info accesed 15.7.2018 from http://www.dorfplanerin.de/Bilder/pyr 2050.gif

[12] Bielek, M.; Bielek, B.; Híreš, J. Technology in Architecture - Low Energy Building versus Green and Sustainable Building, Advanced Materials Research, Vol. 649, pp. 207-210, 2013

[13] Hakoš, V. Barrier - free environment - Kitchen and Bathroom as Living Space In: Young scientist 2010, Tatranská Štrba 2010, TU Košice pg. 1-7. ISBN 978-80-553-0391-8

[14] Lewandowska, A.; Branowski, B.; Joachimiak-Lechman, K.; Kurczewski, P.; Selech, J.; Zablocki, M. Sustainable Design: A Case of Environmental and Cost Life Cycle Assessment of a Kitchen Designed for Seniors and Disabled People. Sustainability 2017, 9, 1329.

[15] Blasco, R.; Marco, Á.; Casas, R.; Cirujano, D.; Picking, R. A Smart Kitchen for Ambient Assisted Living. Sensors 2014, 14, 1629-1653.

[16] Raya, R.; Rocon, E.; Gallego, J.A.; Ceres, R.; Pons, J.L. A Robust Kalman Algorithm to Facilitate Human-Computer Interaction for People with Cerebral Palsy, Using a New Interface Based on Inertial Sensors. Sensors 2012, 12, 3049-3067.

[17] Galajdova, A.; Simsik, D.; Dolina, Z. Testing of e-services for seniors and people with disabilities within e-inclusion project MonAMI. International Journal of Rehabilitation Research, 2009 (32), 75-76.

[18] White, C. Arjo Ratgeber für Architekten und Planer, Arjo Hospital Equipment, Eslöv, Schweden 2005

[19] Francis D.K. Ching, Building Construction Illustrated, hg. John Willey, USA 2014

[20] Zhou, H.; Hou, K.-M.; Zuo, D.; Li, J. Intelligent Urban Public Transportation for Accessibility Dedicated to People with Disabilities. Sensors 2012, 12, 10678-10692.

[21] Georgieff, P. Ambient Assisted Living, Fazit Schriftenreihe, MFG Stiftung Baden Württemberg, Oktober 2008

[22] Jian Li, Yan-jun Zhao, Hui Li, Li-feng Li, Barrier-free interior design for the disabled people DOI:10.1109/ITiME.2011.6130852 Digital Library IEE Xplore 2011 https://ieeexplore.ieee.org/

[23] Bendixen, K. Benktzon, M. Design for All in Scandinavia-A strong concept. Applied ergonomics, 2015, 46: 248-257. 
[24] Brausch, C.; Katunský, D. Changing Social Structure in Europe calls for Tailor-made, Barrier-free Living and new Interior Design, Selected Scientific Papers - Journal of Civil Engineering, 2015 10(1) p. 73-82,

[25] Van Hoof, J.; Boerenfijn, P. Re-Inventing Existing Real Estate of Social Housing for Older People: Building a New De Benring in Voorst, the Netherlands. Buildings 2018, 8, 89.

[26] Meuth, M. Theoretische Perspektiven auf Wohnen: Ein mehrdimensionales Wohnverständnis in erziehungswissenschaftlicher Absicht. In: Meuth M. (eds) Wohn-Räume und pädagogische Orte. Sozialraumforschung und Sozialraumarbeit, vol 16. Springer VS, Wiesbaden, 2017

[27] Chen, Ming-Chuan; Pei-Tseng Kung; Hsun-Pi Su; Suh-May Yen; Li-Ting Chiu and WenChen Tsai, Utilization of tooth filling services by people with disabilities in Taiwan, International Journal for Equity in Health 15(1) 2016

[28] Wallerstedt, B.; Behm, L.; Alftberg, Å.; Sandgren, A.; Benzein, E.; Nilsen, P.; Ahlström, G. Striking a Balance: A Qualitative Study of Next of Kin Participation in the Care of Older Persons in Nursing Homes in Sweden. Healthcare 2018, 6, 46.

[29] Janner, B.; Delboni, MCC.; Ferreira, TG.; Ponte, AS.; Pommerehn, J. Persons with disabilities: Identifying a scenario for the insertion of the occupational therapist in the interior of Rio Grande. Sul. Revisbrat Interinst. Bras. Ter. Ocup. Rio de Janeiro. 2018, v.2(1), p. 68-84

[30] Adamecz-Völgyi, A.; Levay, P.; Bordos, K.; Scharle, A. Impact of a personalised active labour market programme for persons with disabilities, Scandinavian Journal of Public Health 2018, 46(19), 32-48

[31] Barriuso, A.L.; Pérez-Marcos, J.; Jiménez-Bravo, D.M.; Villarrubia González, G.; De Paz, J.F. Agent-Based Intelligent Interface for Wheelchair Movement Control. Sensors 2018, 18, 1511

[32] Barriuso, A.L.; De la Prieta, F.; Villarrubia González, G.; De La Iglesia, D.H.; Lozano, Á. MOVICLOUD: Agent-Based 3D Platform for the Labor Integration of Disabled People. Appl. Sci. 2018, 8, 337 .

[33] Kbar, G.; Abidi, M.H.; Hammad Mian, S.; Al-Daraiseh, A.A.; Mansoor, W. A University-Based Smart and Context Aware Solution for People with Disabilities (USCAS-PWD). Computers 2016, 5,18 .

[34] Gilart-Iglesias, V.; Mora, H.; Pérez-delHoyo, R.; García-Mayor, C. A Computational Method based on Radio Frequency Technologies for the Analysis of Accessibility of Disabled People in Sustainable Cities. Sustainability 2015, 7, 14935-14963. 